\title{
Open MRS softwares: effective approaches in management of patients' health information
}

\author{
Azadeh Bashiri, Marjan Ghazisaeedi*
}

\begin{abstract}
Department of Health Information Management, School of Allied Medical Sciences, Tehran University of Medical Sciences, Tehran, Iran
\end{abstract}

Received: 15 September 2017

Accepted: 07 October 2017

\section{*Correspondence:}

Dr. Marjan Ghazisaeedi,

E-mail: a-bashiri@razi.tums.ac.ir

Copyright: ( ) the author(s), publisher and licensee Medip Academy. This is an open-access article distributed under the terms of the Creative Commons Attribution Non-Commercial License, which permits unrestricted non-commercial use, distribution, and reproduction in any medium, provided the original work is properly cited.

\begin{abstract}
Today, the complexities of health issues require technologies to improve the quality of health care and maintain healthy individuals. Open source softwares such as OpenMRS are the basis for developing electronic health record systems to manage patient health information. Data model, API, and Web-based application are the three main parts of OpenMRS technical architecture. The core of the Open MRS software includes a web-based application and a number of open source softwares such as My SQL, Mozilla Firefox and Hyper net. These softwares use standards such as XML and X-Form to exchange and display data and enhance collaboration with other systems. Also, they can be manipulated and searched using SQL. Considering the high potential of OpenMRS in reducing the cost of implementation and development of electronic health record systems in developing countries, they can be used to manage information of patients and improve the quality of health services.
\end{abstract}

Keywords: OpenMRS, Open source softwares, Electronic health record

\section{INTRODUCTION}

In today's world, due to the spread of science and technology and the complexity of human relationships, health care issues have changed. So, in this new space, it is possible to define technologies such as open source software (OSS) for keeping healthy people. The Open source movement has been founded as the best way to encourage developers to produce high-quality and free software. The open source software has been developed in a cooperative and distributed way that uses the internet and have a license. ${ }^{1,2}$ Licensing has an effective impact on the motivation of developers, and also has an effective role on the users, to accept the software. The examples of such licenses are General Public License (GPL) by Linux and General Public License by the Mozilla Institute. The open source model incorporates the ideas, creativity, and participation of different developers, users, and communities that are willing to support the project. ${ }^{3-5}$ The most important factor for using such softwares is the free use of them by public without any limitations. ${ }^{6}$

For the first time in 2005, Canada Health Infoway introduced the first open source project which enabled hospitals and developers to ensure the safe exchange of patient health records. ${ }^{4,7}$ Along with the development of electronic health records systems to enhance the level of access to patient information and support the clinical and executive activities of health care organizations, in recent years a number of these organizations have been continuously trying to create open-source EHR software. Their goal is to decrease the cost of creating and maintaining electronic health record systems. ${ }^{4,8-11}$

From the other side, every year, millions of people die due to infectious diseases such as AIDS and Tuberculosis. Most of these people are living in developing countries. In response to these pandemic 
mortality, concerted and rapid efforts to create flexible information systems for prevention and treatment of diseases, is needed. The Open MRS is a collaborative effort that can be used as a basis for the development of electronic health records and also the management of patient's health information in developing countries. ${ }^{12-14}$

Initially, the Open MRS was supposed as a general goal for the creation of electronic health record systems. The project has primarily created to manage health information of patients and support a wide range of medical treatments. It was a configurable and open source project which presented electronic medical records applications for providing health care services in developing countries. ${ }^{14,15}$ Open MRS is based on a conceptual dictionary that describes all data items such as clinical findings, laboratory test results and socioeconomic conditions which can be stored in health information systems. With this approach, when adding new concepts, there is no need to modify the database structure and it's easy to share data dictionary between projects. The most important feature of Open MRS is its modular structure, which leads to the planning of new activities without modifying the data structure. Open MRS should only be run by experienced IT professionals who have sufficient knowledge of data structures and clinical systems implementation. ${ }^{15-17}$ The purpose of this study is to highlight the advantages of Open MRS in management of health information of patients.

\section{METHODS}

This narrative review article is conducted by searching articles in scientific databases (SCOPUS \& Google Scholar \& Pub Med) and e-Journal (science direct).

\section{FINDINGS}

The first prototype of Open MRS was created by the Regenstrief Institute in response to the AMPATH project in Kenya for AIDS in February 2004. At the same time, the team for developing electronic medical record at the non-profit healthcare organization (Health Partners in Massachusetts) was looking for ways to develop a medical records system for managing tuberculosis in Peru and AIDS in rural areas of Hawaii. The members of these two projects had common achievements for medical information systems and health care development. So, Open MRS was created as a result of the collaborative efforts of them. ${ }^{12,14,15,18,19}$ Figure 1 shows the OpenMRS software platform.

The first OpenMRS system was implemented in Kenya and followed by Rwanda and South Africa to manage health information in patients with AIDS. Then, these systems were implemented in many countries, including Mozambique, Tanzania, Malawi, Senegal, Uganda and Haiti. The latest major Open MRS project was in January 2010 after Haiti earthquake. This system was used for managing information of injured people. Today, OpenMRS is widely utilized all over the world. ${ }^{4,18,20,21}$

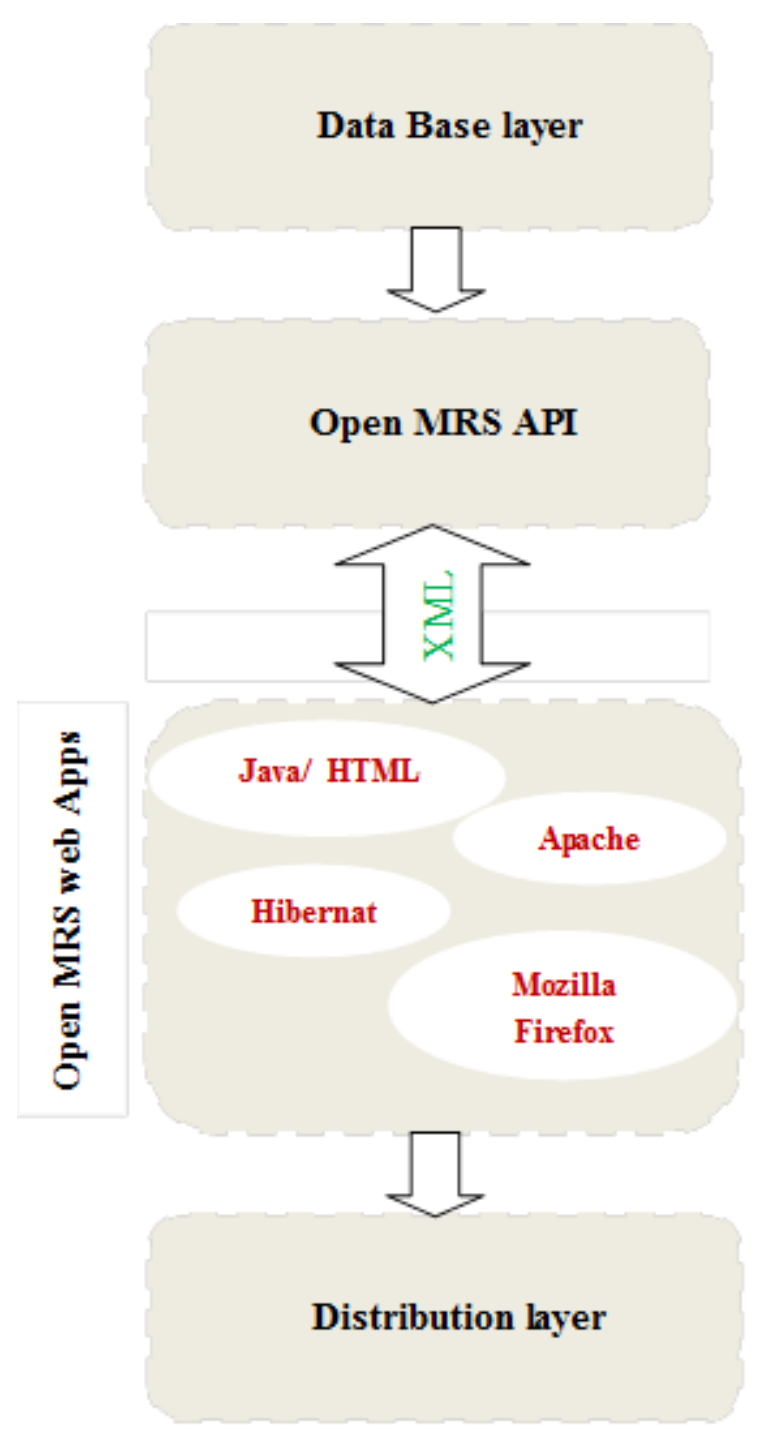

Figure 1: Open MRS software platform.

The technical architecture of OpenMRS is in three main parts including data model, application programming interface (API) and web App. The data model is a data repository which has been designed based on the 30-year history of the medical record system of Regenseric institute. Data model as a patient-centric model guarantees the scalability and flexibility of the system and clearly demonstrates how health care information is stored. It matches with HL7 standard very well and have the capability to support modular programming. There is a conceptual dictionary in the heart of this model. This dictionary contains all of the unique concepts such as questions and answers throughout the system and also default concepts such anatomic sites, diseases, drugs and symptoms. It can provide a flexible way of encoding, searching and saving data., ${ }^{4,}$

The API provides an application for data model and allows developers for programming on an extended scale. 
This part is the interface of the second layer of the system architecture. It includes events and codes which were added by the modules. The data model is inherently complex and is bound by many relationships that the APIs obscure these complexities by coding. ${ }^{12,22}$ The OpenMRS is web-based by default and provides access to the database by connecting to an API. This layer makes it possible to customize the web-based environment. It includes a wide range of useful tasks including; data warehouse creating and storing, conceptual directory management, clinical data management, user management, role management and forms management. This layer is written using JAVA, JSP and HTML, and provides a bridge between the clients and the server. ${ }^{12,14}$

The core application of the Open MRS software includes a web application, which is based on Java and JavaScript, and numbers of open source software such as My SQL, Apache, Tomcat, Mozilla Firefox and Hybrid. All of the components in this software use the form entry module. This module allows developing forms for recording and saving data. OpenMRS has developed standards to enhance collaboration with other systems in order to support the server-client and the distributed applications. Standards such as XML and X-Form are used for exchanging and displaying data and forms. By using these standards, data is exchanged between Form Entry and App Layer Package. ${ }^{4,14}$

\section{DISCUSSION}

EHR systems provide useful and suitable information for making the best decision about the health care services which deliver to individuals. Along with improving health care, by applying EHR, medical errors can be declined. Regarding the necessity of accepting health and medical informatics softwares, open source solutions have been considered in the health care institutions. ${ }^{4,23,25}$ Open source softwares are intermediary tools for development of health care applications and at the same time have a high potential for supporting the health information systems. ${ }^{6,14}$ Over the past years, serious efforts have been made to create open source electronic health record systems. The greatest benefit of OpenMRS is it's flexibility to adapt to the specific needs of any center. Previous studies indicated a growing interest in Open source softwares among the health care organizations. ${ }^{4,6,23-25}$ Creating Open MRS systems through reducing the cost of installation, maintenance and update of the electronic health record systems, will lead to the more cost savings for physicians and other health care providers. They can lead to the better information management of patients and improve the quality and efficiency of health care services. ${ }^{24}$

Funding: No funding sources Conflict of interest: None declared

Ethical approval: Not required

\section{REFERENCES}

1. Paré G, Wybo MD, Delannoy C. Barriers to open source software adoption in Quebec's health care organizations. J Medical Systems. 2009;33(1):1-7.

2. Kgomotso HM, Kelvin Joseph B, Peter Mazebe IIS, editors. Health Information Systems and the Advancement of Medical Practice in Developing Countries. Hershey, PA, USA: IGI Global; 2017.

3. Economides N, Katsamakas E. Two-sided competition of proprietary vs. open source technology platforms and the implications for the software industry. Management Sci. 2006;52(7):1057-71.

4. Janamanchi B, Katsamakas E, Raghupathi W, Gao $\mathrm{W}$. The state and profile of open source software projects in health and medical informatics. Int $\mathbf{J}$ Med Informatics. 2009;78(7):457-72.

5. License GGP. GNU General Public License. Retrieved December. 1989;25:2014.

6. Maglogiannis I. Towards the adoption of open source and open access electronic health record systems. J Healthcare Engineering. 2012;3(1):14161.

7. Luna D, Almerares A, Mayan JC, Gonzalez Bernaldo de Quiros F, Otero C. Health informatics in developing countries: going beyond pilot practices to sustainable implementations: a review of the current challenges. Healthcare informatics research. 2014;20(1):3-10.

8. Sadoughi F, Delgoshaei B, Foozonkhah S, Tofighi $\mathrm{S}$, Khalesi N. Designing an object-oriented model for some key messages to support the electronic health record. J Health Admin. 2006;9(25):21-30.

9. Reynolds CJ, Wyatt JC. Open source, open standards, and health care information systems. J Medical Internet Res. 2011;13(1):24.

10. Ahmadi M, Bashiri A. A minimum data set of radiology reporting system for exchanging with electronic health record system in Iran. J Payavard Salamat. 2014;8(2):121-33.

11. Ahmadi M, Ghazisaeidi M, Bashiri A. Radiology Reporting System Data Exchange With the Electronic Health Record System: A Case Study in Iran. Global J Health Science. 2015;7(5):208.

12. Cooking up an open source EMR for developing countries: OpenMRS-a recipe for successful collaboration. In: Mamlin BW, Biondich PG, Wolfe BA, Fraser H, Jazayeri D, Allen C, et al, editors. AMIA Annual Symposium Proceedings; 2006: American Medical Informatics Association.

13. AMPATH Medical Record System (AMRS): collaborating toward an EMR for developing countries. In: Mamlin BW, Biondich PG, editors. AMIA Annual Symposium Proceedings; Am Med Informat Assoc, 2005.

14. Seebregts CJ, Mamlin BW, Biondich PG, Fraser HS, Wolfe BA, Jazayeri D, et al. The OpenMRS implementers network. International journal of medical informatics. 2009;78(11):711-20. 
15. Siika AM, Rotich JK, Simiyu CJ, Kigotho EM, Smith FE, Sidle JE, et al. An electronic medical record system for ambulatory care of HIV-infected patients in Kenya. International journal of medical informatics. 2005;74(5):345-55.

16. Häyrinen K, Saranto K, Nykänen P. Definition, structure, content, use and impacts of electronic health records: a review of the research literature. Int J Med Informat. 2008;77(5):291-304.

17. De Clercq E. From a conceptual problem-oriented electronic patient record model to running systems: A nationwide assessment. Int $\mathrm{J}$ Med Informat. 2008;77(5):346-53.

18. Aminpour F, Sadoughi F, Ahamdi M. Utilization of open source electronic health record around the world: A systematic review. J Res Med Sci. 2014;19(1):57-64.

19. Mohammed-Rajput NA, Smith DC, Mamlin B, Biondich $\mathrm{P}$, Doebbeling BN, Investigators OMC, editors. OpenMRS, a global medical records system collaborative: factors influencing successful implementation. AMIA annual symposium proceedings; American Medical Informatics Association, 2011.

20. Kanter AS, Negin J, Olayo B, Bukachi F, Johnson E, Sachs SE. Millennium global village-net: Bringing together millennium villages throughout sub-Saharan Africa. Int $\mathrm{J}$ Med Information. 2009;78(12):802-7.
21. Forster M, Bailey C, Brinkhof MW, Graber C, Boulle A, Spohr M, et al. Electronic medical record systems, data quality and loss to follow-up: survey of antiretroviral therapy programmes in resourcelimited settings. Bulletin of the World Health Organization. 2008;86(12):939-47.

22. Allena'b C, Jazayeri D, Miranda J, Biondich PG, Mamlinc BW, Wolfe BA, et al. Experience in Implementing the OpenMRS Medical Record System to Support. Medinfo. 2007;129:382.

23. Kantor GS, Wilson WD, Midgley A. Open-source software and the primary care EMR. BMJ Group BMA House, Tavistock Square, London, WC1H 9JR; 2003.

24. Øyri K, Murray PJ. osni. info-Using free/libre/open source software to build a virtual international community for open source nursing informatics. Int $\mathbf{J}$ Med Informatics. 2005;74(11):937-45.

25. Reynolds CJ, Wyatt JC. Open source, open standards, and health care information systems. J Med Internet Res. 2011;13(1):24.

Cite this article as: Bashiri A, Ghazisaeedi M. Open MRS softwares: effective approaches in management of patients' health information. Int J Community Med Public Health 2017;4:3948-51. 